\title{
The Formal and Informal Long-Term Caregiving for the Elderly: The Malaysian Experience
}

\author{
Zheng-Yi Goh ${ }^{1}$, Ming-Ming Lai ${ }^{1}$, Siok-Hwa Lau ${ }^{2} \&$ Nazihah Ahmad ${ }^{3}$ \\ ${ }^{1}$ Faculty of Management, Multimedia University, Cyberjaya, Malaysia \\ ${ }^{2}$ Centre for Foundation Studies and Extension Education, Multimedia University, Melaka, Malaysia \\ ${ }^{3}$ Centre for Foundation Studies and Extension Education, Multimedia University, Cyberjaya, Malaysia \\ Correspondence: Siok-Hwa Lau, Centre for Foundation Studies and Extension Education, Multimedia University, \\ Jalan Ayer Keroh Lama, 75450 Bukit Beruang, Melaka, Malaysia. Tel: 60-6-252-3976. E-mail: \\ shlau@mmu.edu.my
}

Received: January 20, 2013 Accepted: February 18, 2013 Online Published: March 28, 2013

doi:10.5539/ass.v9n4p174 URL: http://dx.doi.org/10.5539/ass.v9n4p174

\begin{abstract}
This paper examines the formal and informal caregiving for elderly in the Malaysian society under the absence of a structured long-term care environment. We surveyed 31 health care providers and 56 informal caregivers for elderly. The private for-profit care providers offer better facilities and services than non-profit centres. Females especially daughters were usually the informal caregivers to the elderly. Caregivers spent below USD $\$ 330$ on long-term care expenses and relying heavily on public health care services. The results suggest government to implement a comprehensive social insurance for long-term care to ensure protection and equal treatment to be received by elderly.
\end{abstract}

Keywords: caregiving, long-term care, community and home care, formal care, informal care

\section{Introduction}

According to the United Nations (2008), Malaysia is expected to become an ageing nation by 2030 in which $15 \%$ of its population were aged 60 years and above. Beard (2010) indicated that the ageing populations would increase the demand of long-term care rather than acute care. However, compared to other developed nations, Malaysia does not have necessary safety net such as long-term care insurance, private pension schemes, annuity income, and social security benefits for its retirees and aged senior citizens (Yip, 2012). Are Malaysians preparing to face the challenges of the ageing society? Bernama (2011) indicated that Malaysia's preparation for ageing population would require reformation in all social policies ranging from healthcare to public facilities for the elderly. Moreover, Chong (2011) also indicated that there was a gap between public and private roles in contributing to the ageing and long-term care system. It is worth noting that the modernisation process brings the societal changes which would directly or indirectly influence caregiving as well as the status of older people occupy in society.

In the absence of long-term care insurance and social security benefits, Malaysians mostly rely on informal care and some formal care for health care needs of the elderly. In Japan, Hanaoka and Norton (2008) showed that families living in 3-generation households have decreased from $46 \%$ in 1985 to $20.5 \%$ in 2006 . Moreover, with urbanisation, it has increased the migration of young workforce to cities, leaving ageing parents behind to live by themselves. They suggest providing an age-friendly environment to encourage the active elderly to participate and continue contributing to society as well as enhancing their quality of life.

Hence, this paper is motivated to examine long-term care practices from the perspectives of formal care providers and informal caregivers for the elderly at home in Malaysia. The questions raised in this study is what extent is the long-term care for the elderly in Malaysia deliver and cope with the demand for the ageing population in near future? We surveyed two groups of target respondents, namely, the informal caregivers of the elderly at home and formal care providers in central regions of west Malaysia. The survey of informal caregivers explored the care received by the elderly at home whereas the survey of formal care providers studied the services, infrastructure, and facilities provided by them for elderly. The study not only add new empirical evidence to the existing literature by providing better understandings and knowledge about long-term care for the elderly, but also fill the gaps of 
limited research in Malaysia on formal and informal caregiving. Better understandings are needed for social policy reformation.

\section{Literature Review}

In Malaysia, the definition of elderly is an individual aged 60 and above based on the recognition attained from "World Assembly on Ageing 1982" in Vienna (Department of Social Welfare, 2012).

Choo et al. (2003) examined the social support and burden of 70 caregivers of patients with dementia in Malaysia. They used Zarit Burden interview measures which included the patient and caregivers demographics. The results showed that Chinese caregivers had higher burden when compared to Malays and Indians, and the burden was significantly related to the both ethnic groups and cultures. As expected, daughters remain the most caregivers. Despite $36 \%$ caregivers received assistance from maids or private nurses; they did not alleviate the burden of caregivers. Interestingly, informal support from family members would lower the burden perceived by the caregivers in which it would help to share the caregiving responsibilities and relieved the chief caregiver on a temporary basis.

Chee (2008) highlighted the incompleteness of healthcare transformation that spare out the funding issues generating gap between those that can afford to pay for private service and those who cannot afford to pay. The inequity in the healthcare system greatly affects low-wages groups and the elderly as they have limited income.

Hanaoka and Norton (2008) examined whether the use of informal care by adult children and how their characteristics affected the use of formal care in Japan. They studied 1450 single elderly parents aged 65 years and above from the collected data of the 2001 wave of the Nihon University Japanese Longitudinal Study of Ageing. The results showed that marital status and the opportunity costs of time for the children were very crucial factors in deciding whether to provide informal care for the elderly parents or not. The traditional role of daughter-in-law caregivers was becoming less important than unmarried children. Children with lower opportunity cost significantly reduced the reliance of formal long-term care. The lesser educated unmarried children appeared to be the substitutes for formal long-term care. This result had policy implication in which it proposed a policy change in the eligibility for formal long-term care by using the health status of the elderly as a criterion rather than the availability of family support which was being practised in Japan.

The Japanese society has begun to realise the importance of "advance directives" to ensure better care given to the elderly before the elderly losses his or her ability to convey his or her wishes. Matsui (2010) through a 90 minute direct educational programme based on 121 adults aged 65 and above, carried out over a period of two months revealed a significant shift in the elderly's mind-set. From a high $45.5 \%$ of pre-intervention response on leaving the treatment decision to a physician to decide at the final critical stage of illness to $24.5 \%$ of post-intervention, Japanese elderly have begun to learn to take charge of their life as to how they wished to live. Matsui (2010) also pointed out that "advance directives" awareness was much more successful when it was carried on a one to one basis as compared to the distribution of pamphlets or flyers.

Collet, de Vugt, Verhey and Schols (2010) indicated that nowadays people were prone to develop or suffer from more than one type of illness or complication. Hence, nursing homes should be prepared to provide a comprehensive care that would cater to a more complex need in order to assist the elderly to cope, recover and/(or) improve their condition. A typical complex illness would be an elderly suffering from dementia combined with psychiatric disorders; hence he or she would certainly need a nursing home that is equipped with professional expertise in both psychiatric and nursing care.

Gustafsdottir (2011) studied care programmes carried out by three day care centres for the elderly with dementia in Iceland. Iceland had the Iceland Act on Care for the Elderly for day care centres to abide by. "Day care for the elderly (belongs to open care for the elderly) is a support measure for those who require constant supervision and care to be able to continue living at home. Day care for the elderly should include nursing care. It should also provide transport to and from the individual's home, health assessment, training, leisure activities, social support, education, consultation, and assistance with the activities of daily living".

The unskilled home based care can be enhanced by community support care. In addition to day care centres, meals on wheel and home assistance care, there are increased demand to look into a more advanced and complex care that the community can provide. More and more community care supports are able to provide top-notch cost effective and efficient automation care tapping on the advancement of technology (Camarinha-Matos \& Afsarmanesh, 2002).

Boissy, Corriveau, Michaud, Labonté, and Royer (2007) explored the possibility of mechanical care, using robots for home-based care for the elderly in Canada. The advancement of technology and the increasing difficulty in 
providing home-based care for elderly who wish to continue living at home and were unable due to the shortage of resources from family members, had encouraged developed countries to search for alternatives to complement or replace home-based care that was not formal care. Two focus groups were set up for the study with one comprised six professional physicians and the other six elderly in need of care. The results from the interviews with these two groups reached a unify feedback that the concept of robotics care could provide support to a home-based caregiver but could not fully substitute the role of the caregiver as machines were still unable to provide mental and emotional care and support. The robotics care concept was only feasible in providing assistance in activities of daily living, home help, health and medical monitoring, and worked as an emergency response system when the caregiver was away.

Kuzuya, Izawa, Enoki, and Hasegawa (2011) examined the impact of informal care levels on discontinuation of living at home by using 1582 community-dwelling disabled elderly and paired informal caregivers during the 3 -year study period in Japan. The results indicated that "an insufficient informal care level was associated with overall discontinuation of living at home, all-cause mortality, hospitalisation, and institutionalisation during 3 years of follow-up (p.127)". The results suggest the importance of informal caregiving to prevent from overall discontinuation of living at home.

Back in Malaysia, the social and welfare department oversees 15 day care centres (Pusat Jagaan Harian Warga Emas), seven homes for the elderly (Rumah Seri Kenangan), two nursing homes (Rumah Ehsan), and two shelter homes (Deasa Bina Diri) (Zaimi, 2007). In addition, Malaysia's Department of Social and Welfare also provides counselling and psychology care for the elderly and their family member who are assisting in nursing and caring for the elderly (Department of Social Welfare, 2011).

\section{Data and Method}

This study comprises of two groups of target respondents who are the informal caregivers and the formal care providers in West Malaysia. Two set of questionnaires were developed in which the formal care providers' questionnaire explored the care provided while the informal caregiver questionnaire explored the care received by the elderly at home. Caregiver in this study is defined as someone who provides care for an elderly who needs assistance in performing daily living activities. Questions in both questionnaires were mainly developed that allowed respondents to tick their responses while Likert scale questions allowed the respondents rated their perception.

The questionnaire of the formal care providers was divided into three parts, Section A, Section B, and Section C. Section A consists of questions on demographic variables such as gender, race, age, marital status, language spoken, education background, occupation, and years of service. This would provide general background information on the care providers as their education background and the years of care experience could determine the service quality they provide. Section B consists of questions covering background information on the institution, the care provided, and the facilities available. This section of the questionnaire would provide information on the form of operation, numbers of residents, types of residents admitted, numbers of care providers and fees structure. The variables in Section B pertaining post-hospital care in daily activities for care and facilities provided by the care providers were adapted from Chuang, Wu, Dai and Ma (2007). Section C consists of eight structured questions directed to the supervisors or administrators of nursing home on the general operations, care programmes, and opinions or recommendation on long-term care for the aged. Past studies stated that in addition to facilities established in nursing homes, quality of care programmes is important to develop and support the elderly.

Informal caregiver questionnaire is divided into five parts, namely, Section A, Section B, Section C, Section D and Section E. Similarly to formal care provider's questionnaire, section A consists of questions on demographic variables for caregiver based on gender, race, age, marital status, location, education background, and household monthly income. The demographic variables are to give an overall knowledge or understanding of the respondents' background. Section B consists of questions on demographic variables of the elderly in need of care covering from the relation between the caregivers and the elderly, assistance received, gender, age, duration of long-term care need for the elderly, health status of the elderly, elderly's desire on living arrangement, elderly's current living arrangement. Components for caregivers and the elderly's demographics variables were constructed and modified based on Kuzuya et al. (2011). Caregivers relationship towards quality of care as studied by Hanaoka and Norton (2008) were also included in the construction of informal caregivers' questionnaire.

\section{Results}

The results of two surveys are analysed and discussed below. First, we discussed the results of care providers and then follow by the results of caregivers. 


\subsection{Survey Results of Care Providers}

The results showed that 31 care providers in which 22 were female and 9 were male participated in the study. Overall, the results indicated that most of the nursing workers in the care provider centres were foreign helpers. They were mainly from the Philippines, Indonesia and Sri Lanka and aged between 21 to 30 years old. Local care providers were mainly in charge of the service centres and in managerial, administrative and supervisory positions. Among the local races, Indians are the ones most involved in elderly nursing care. English and Malay languages were found to be the most common language in communication used by the care providers.

Pearson correlation tests were performed on the care providers' education qualification and years of services in care centre. The result showed a significantly negative correlation of -0.480 . The care providers who obtained higher qualifications had less years of service as compared to those with lower qualifications. This further indicated that jobs turnover among the care providers with higher qualifications are greater as they are in a better position for other job opportunities as compared to those with lower qualification.

The findings above justify the brief conversation by one of the care providers on the shortage of quality staff. Conversation is quoted as below:

“Too many inmates - difficult to get helpers - do you know that we Chinese don't work in a nursing home - since I open till now nobody ever worked here - mostly Indian girls helping - only this year I have one Indonesian girl - all and all is Indian girls - only them are willing to do this job - sometimes when my patient are a bit rude -I tell them don't be rude to these people - they are only human and they are only the one who can look after you - don't you think so - we must have mutual respect - doesn't mean they are workers you can look down and mistreat them - so is not easy - I appreciate them - tell me who can manage this - is not a very pleasant job - you people must be very thankful to them"

The findings on language spoken by care providers also raised a concern by one respondent that many elderly especially the Chinese only communicate in their own dialects with minimal ability to communicate--Mandarin, English or Bahasa Malaysia. Communication breakdown between care providers and the elderly could affect the quality of care.

Table 1. Types of residents in formal care institutions

\begin{tabular}{lccc}
\hline & & Types of formal care institutions (care providers) \\
Types of residents & Public (\%) & Private for-profit (\%) & Private non-profit (\%) \\
\hline Healthy & 12.9 & 48.4 & 25.8 \\
Temporary assistance & 6.5 & 54.8 & 19.4 \\
Long-term care & 6.5 & 51.6 & 9.7 \\
Destitute & 9.7 & 0.0 & 29.0 \\
\hline
\end{tabular}

Table 1 reports three types of formal care institutions in Malaysia. The first is public, established by the government under the supervision of the Department of Social and Welfare. The second is provided by private corporations where residents are required to pay monthly fees for the facilities, care and support. The third type of institution is established by the generous public and non-government organisations for charitable purposes. Generally, the public and private non-profit care institutions provide shelters to the poor and abandoned elderly with minimum care and supervision; hence admissions to these institutions would require the elderly to be healthy and self-manageable. The elderly who need frequent supervision and long-term care would need access to private for-profit care institution. The care providers further revealed that the identity of the elderly are private and confidential especially for those whose children or family members who do not wish to let others know that their elderly are staying in an institution. Hence, the children's characteristics of these elderly as well as the personal characteristics of the elderly in the care centres could not be studied.

The public care institutions do not charge residential fees. Standard monthly fees charged by private for-profit care institution are between RM1001 to RM3000. Private non-profit care institutions normally do not charge its residents. It is the choice of the residents to contribute or donate to the institutions.

Table 2 presents the mean and standard deviation of availability of facilities, care services, equipment, support and 24-hour assistance provided by the care institutions. On average, activity areas scored the highest mean of 3.71, 
indicating that this is the most common facility available in care institutions. Managing medication scored the highest mean of 3.45, indicating that care providers help to manage the residents' medication supply and intake. Wheelchair scored the highest mean of 3.58 as the most available equipment in care institutions. Management of medical record scored the highest mean of 3.45, indicating that medical record of the residents' health status is a must for all care institutions. The care providers had indicated all 24-hour assistance facilities from feeding to mobility.

Table 2. Descriptive statistics of availabilities of facilities, care services, equipment, support services and 24-hour assistance by care institutions

\begin{tabular}{|c|c|c|c|c|}
\hline \multirow{2}{*}{\multicolumn{2}{|c|}{ A. Facilities: }} & \multirow{2}{*}{$\begin{array}{c}\text { Cronbach's alpha } \\
0.671\end{array}$} & \multirow[t]{2}{*}{ Mean } & \multirow[t]{2}{*}{ Standard deviation } \\
\hline & & & & \\
\hline & 1. Personal room with special needs & & 2.65 & 1.279 \\
\hline & 2. Shared room with special needs & & 3.32 & 1.045 \\
\hline & 3. Personal utensil & & 3.23 & 0.920 \\
\hline & 4. Dining area & & 3.61 & 0.715 \\
\hline & 5. Reading area & & 3.00 & 1.095 \\
\hline & 6. Activity area & & 3.71 & 0.461 \\
\hline & 7. Prayer room & & 2.23 & 1.230 \\
\hline & 8. Gym & & 2.65 & 1.050 \\
\hline & 9. Garden & & 3.58 & 0.720 \\
\hline & 10. Elderly safe washroom & & 3.61 & 0.558 \\
\hline B. & Care Services: & 0.967 & & \\
\hline & 1. Feeding & & 3.19 & 1.223 \\
\hline & 2. Cleaning & & 3.35 & 1.082 \\
\hline & 3. Dressing & & 3.42 & 1.025 \\
\hline & 4. Using toilet & & 3.39 & 1.022 \\
\hline & 5. Mobility & & 3.39 & 1.054 \\
\hline & 6. Health monitoring & & 3.32 & 1.045 \\
\hline & 7. Monitoring nutrition and diet & & 3.19 & 0.980 \\
\hline & 8. Customised meals & & 2.81 & 1.046 \\
\hline & 9. Managing medication & & 3.45 & 1.028 \\
\hline & 10. Personal physiotherapy & & 2.71 & 1.270 \\
\hline C. & Equipment: & 0.693 & & \\
\hline & 1. Wheelchair & & 3.58 & 0.923 \\
\hline & 2. Walker & & 3.52 & 0.890 \\
\hline & 3. Electrical bed & & 3.03 & 1.197 \\
\hline & 4. Bath bench & & 3.19 & 1.108 \\
\hline & 5. 24-hour emergency response system & & 2.61 & 1.145 \\
\hline D. & Support Services: & 0.886 & & \\
\hline & 1. Transport & & 2.94 & 1.153 \\
\hline & 2. In-house physician & & 2.58 & 1.205 \\
\hline & 3. Management of medical record & & 3.45 & 0.888 \\
\hline & 4. Therapeutic treatment & & 2.61 & 1.145 \\
\hline
\end{tabular}


5. Rehabilitation

6. Counselling care

7. Review of medicine

8. Medical check-up arrangement

E. 24-hour Assistance:

1. Feeding

2. Cleaning

3. Dressing

4. Mobility

5. Using toilet
3.23

0.994

$\begin{array}{ll}3.26 & 1.125 \\ 3.29 & 1.160 \\ 3.26 & 1.154 \\ 3.29 & 1.131 \\ 3.26 & 1.210\end{array}$

1.210

Notes: 1 The respondents were asked to record their responses by indicating the availability of each statement on a 4-point scale fixed on 1 (unavailable) to 4 (highly available).

2 Facilities, care services, equipment, and support services showed significant correlations of $0.694,0.443,0.579$, and 0.562 with monthly fees charged by formal care providers.

Table 2 also showed significant correlation results between the availability of facilities, equipment, and support and the monthly fees charged by the care institutions. The test was only performed on private for-profit care institutions because the other two institutions did not charge any fees. The findings indicated that private for-profit care institutions provided better facilities, equipment and support care would charge higher fees as compared to others.

\subsection{Survey Results of Caregivers}

The study received responses from 56 informal home-based caregivers in central regions in Malaysia. Expectedly, there were more female caregivers compared to male in which 38 of informal caregivers were female while males were 18. Overall, more Chinese caregivers participated in this study compared to Malay, Indian and other races, with the percentage being 53.5 for Chinese, 32.1 for Malay, 12.5 for Indian, and 1.8 from others. Most caregivers were age between 31 to 40 years old representing $34.1 \%$ of the entire sample, followed by $28.7 \%$ caregivers aged between 41-50 years old. The results showed that most of the care givers are still working, juggling between work and family. Most informal caregivers are daughters to the elderly from the working age between 30 to 50 years. Hence, this group of caregivers relies heavily on the assistance of foreign maid and other siblings in taking care of the elderly. They further expressed the community support preference where home-help and home nursing care received greater response compared to others. On the other hand, unmarried children are providing informal care to the elderly parents. The trend is somewhat consistent with the findings of Hanaoka and Norton (2008).

As a whole, 38 female and 18 male elderly who are receiving informal home-based care participated in this study. About $30.36 \%$ of the elderly receiving informal cares are from the age group between 71-75 years old. Most elderly suffer from a combination of chronic disease such as hypertension, diabetes, stroke and other diseases. They receive the most attention. Daughters caregivers are the largest group with a total of $39.3 \%$, follow by sons of the elderly (see Table 3). At the same time, we also found that the traditional roles of daughter-in-laws as caregivers were becoming less important. These results are consistent with the findings of Choo et al. (2003) as well as Hanaoka and Norton (2008). These informal caregivers also receive assistance and support from their siblings (39.3\%) and maids (26.8\%), respectively.

Among the 56 caregivers, only $33.9 \%$ of the caregivers responded that the elderly spoke about their desire as they age. The elderly spoke of their desire to either live on their own in their homes or to live with their children. The remaining $66.1 \%$ without desired spoken also perceived that own home and children's home were the preference of their elderly. Current living arrangements showed that most elderly are now residing with their caregivers. Most male elderly are living with their spouse as compared to their female counterpart. This is indicative that of the higher life expectancy among the elderly as well as females gender role that makes women caregivers as compared to men while they were most likely in need of care themselves as well. 
Table 3. Caregivers' relationships to elderly and marital status of caregivers

\begin{tabular}{lcccc}
\hline Caregivers & Frequency & Per cent & Married & Single \\
\hline Spouse & 4 & 7.1 & 4 & 0 \\
Son & 12 & 21.4 & 7 & 5 \\
Daughter & 22 & 39.3 & 18 & 4 \\
Brother/sister & 2 & 3.6 & 1 & 1 \\
Grandson & 2 & 3.6 & 1 & 1 \\
Granddaughter & 4 & 7.1 & 0 & 4 \\
Son-in-law & 1 & 1.8 & 1 & 0 \\
Daughter-in-law & 8 & 14.3 & 8 & 0 \\
Foreign maid & 1 & 1.8 & 0 & 1 \\
Total & 56 & 100.0 & 40 & 16 \\
\hline
\end{tabular}

Table 4. Descriptive statistics of availability of elderly-friendly equipment, and weightage of monthly elderly care expenditure

\begin{tabular}{llcc}
\hline & & Mean & $\begin{array}{c}\text { Standard } \\
\text { Deviation }\end{array}$ \\
\hline A. Elderly-Friendly Equipment* & $\begin{array}{c}\text { Cronbach's } \\
\text { Alpha }\end{array}$ & & \\
1. Electrical bed & 0.683 & & 0.733 \\
2. Wheelchair & & 1.41 & 1.354 \\
3. Walker/cane & & 2.36 & 1.317 \\
4. Handrail & & 2.21 & 1.032 \\
5. Seated toilet & & 2.09 & 0.990 \\
6. Bath bench & 3.46 & 1.032 \\
7. Non-skied floor mat/carpet & & 2.34 & 0.903 \\
8. Emergency sensor agent & & 2.64 & 0.568 \\
B. Weightage of Monthly Elderly Care Expenditure** & 0.594 & 1.43 & 1.064 \\
1. Personal care products (e.g. adult diapers) & & 2.82 & 0.853 \\
2. Medication & & 3.23 & 0.862 \\
3. Physician check-up & & 2.86 & 1.062 \\
4. Therapy and rehabilitation visit & & 2.00 & 0.548 \\
5. Psychology and counselling & & 1.25 & 1.332 \\
6. Maid/helpers/professional assistance pay & & 2.16 &
\end{tabular}

Notes:* The respondents were asked to record their responses by indicating the availability of each statement on a 4-point scale fixed on 1 (unavailable) to 4 (highly available). ${ }^{* *}$ The respondents were asked to record their responses by indicating the weightage of each statement on a 4-point scale fixed on 1(Not applicable) to 4 (Highly weighted).

Next, among the elderly-friendly equipment or assistive device that caregivers prepare for the elderly is seated toilet which scored the highest mean of 3.46. The findings indicated that medical expenses and personal care products are the most costly expenditure for long-term care for elderly (see Table 4).

On the other hand, the caregivers perceived that elderly's behaviour and emotions are the most challenging to handle as the results indicated the highest mean scored of 4.25. In terms of expenditure resources for the elderly, the care givers indicated that personal savings and out-of-pocket expenses are the most common resource for long-term care funding with a mean of 3.82 and 3.48, respectively (see Table 5). 
Table 5. Descriptive statistics of challenges of elderly caregiving and expenditure sources

\begin{tabular}{|c|c|c|c|c|}
\hline & & $\begin{array}{l}\text { Cronbach's } \\
\text { Alpha }\end{array}$ & Mean & $\begin{array}{l}\text { Standard } \\
\text { Deviation }\end{array}$ \\
\hline \multicolumn{2}{|r|}{ A. Challenges of Elderly Caregiving* } & 0.753 & & \\
\hline & 1. Preparation of nutrition meals & & 3.46 & 1.206 \\
\hline & 2. Cleaning/bathing/grooming the elderly & & 3.61 & 0.985 \\
\hline & 3. Monitoring and managing medical intake & & 3.50 & 1.144 \\
\hline & $\begin{array}{l}\text { 4. Transferring the immobilised elderly (e.g. from bed to } \\
\text { chair) }\end{array}$ & & 3.89 & 1.056 \\
\hline & 5. Handling elderly's behaviour and emotion & & 4.25 & 0.919 \\
\hline & 6. Lack of support & & 3.59 & 1.218 \\
\hline & 7. Work obligation & & 3.73 & 0.981 \\
\hline & 8. Financial obligation & & 3.79 & 0.986 \\
\hline & 9. Stress and mentally challenged & & 3.89 & 0.985 \\
\hline & Expenditure Sources of Elderly Care** & 0.479 & & \\
\hline & 1. Personal savings & & 3.82 & 1.428 \\
\hline & 2. Employee provident fund (EPF) & & 1.77 & 1.144 \\
\hline & 3. Pension & & 2.29 & 1.659 \\
\hline & 4. Private insurance & & 1.39 & 0.928 \\
\hline & 5. Out-of-pocket & & 3.48 & 1.549 \\
\hline & 6. Employee benefit scheme & & 1.48 & 1.062 \\
\hline & 7. Social welfare financial assistance & & 1.71 & 1.155 \\
\hline & 8. Donation & & 1.21 & 0.594 \\
\hline
\end{tabular}

Notes: * The respondents were asked to record their responses by indicating their agreement with each statement on a 5-point scale fixed on 1 (Strongly disagree) to 5 (Strongly agree). ${ }^{* *}$ The respondents were asked to record their expenditure sources by indicating the priority of each source on a 5-point scale fixed on 1 (Not applicable) to 5 (Tertiary source).

Table 6 shows household monthly income for caregivers and monthly expenditure for the elderly. Generally, most home-based caregivers spend below RM1000 for elderly care.

Table 6. Household monthly income for caregivers and elderly care monthly expenditure

\begin{tabular}{lll}
\hline Panel A: Household Monthly Income of Caregiver (RM) & Frequency & Per cent \\
\hline Below 3000 & 23 & 41.1 \\
$3001-6000$ & 14 & 25.0 \\
$6001-10000$ & 11 & 19.6 \\
$10001-15000$ & 5 & 8.9 \\
$15001-20000$ & 2 & 3.6 \\
Above 20000 & 1 & 1.8 \\
Panel B: Elderly Monthly Expenditure & Frequency & Per cent \\
Below 1000 & 31 & 55.4 \\
$1001-2000$ & 19 & 33.9 \\
$2001-5000$ & 6 & 10.7 \\
Total & 56 & 100.0 \\
\hline
\end{tabular}


The respondents were asked to indicate his or her preference from the community support services that would ease elderly care (Table 7). They may choose more than one preference. The survey results showed that the choices of community support desired by the caregivers are home-help care (57.1\% from the total group) and home nursing service (46.4\% from the total group). This is understandable as most the caregivers are aged between 31 to 50 years who are still active in the workforce and are classified as sandwich generations.

Table 7. Community support care preferences by caregivers

\begin{tabular}{lcc}
\hline Types of Community Support Services & Frequency & Per cent \\
\hline Acupuncture centre & 8 & 14.3 \\
Ambulance/emergency transit & 25 & 44.6 \\
Counselling/befriender service & 18 & 32.1 \\
Elderly care training & 11 & 19.6 \\
Flexible work hours & 20 & 35.7 \\
Home help service & 32 & 57.1 \\
Home nursing service & 26 & 46.4 \\
Hotline service & 15 & 26.8 \\
Nutrition meals on wheels & 15 & 26.8 \\
Physical therapy centre & 10 & 17.9 \\
Senior citizens' club & 14 & 25.0 \\
Social day care & 13 & 23.2 \\
Speech therapy centre & 3 & 5.4 \\
Support group service & 17 & 30.4 \\
Third party agency (emergency supervisor agent) & 1 & 1.8 \\
Others & 1 & 1.8 \\
\hline
\end{tabular}

Based on the community welfare and support, public and private clinics are the most common community infrastructure available within 10 kilometres away from the caregivers followed by pharmacies, dental clinics, and hospitals. The respondents ranked clinics as the nearest available community facilities available below 10 kilometres. However, discrepancies of responds for the distance of hospitals are found between the respondents from the cities and rural areas. The inadequate community and welfare infrastructure in the rural areas of Melaka has deprived most of the elderly immediate and good quality medical care. The lack of personal and public transportation has discouraged many elderly to continue physical check-ups and to visit any specialist, as most general hospitals are quite a distance. The establishments of private hospitals in urban areas often target those who can afford to pay for the medical care has generated a huge gap in medical care. Those from rural areas who are hindered by the distance and cannot afford private hospitals are usually subjected to lower quality care from overcrowded public facilities and care. Physician on wheels is proposed to cater to the elderly that have no access to community support and care. Rakan Bangkit Mobile Clinic for example, is a mobile clinic that reaches out to deliver healthcare to the public which include traditional Chinese medical treatment such as acupuncture and massage.

Approximately $50.0 \%$ of the urban respondents ranked hospital facilities located within 10 kilometres away from them, while only $19.4 \%$ respondents from non-urban areas ranked hospital facilities within10 kilometres from them. This finding is consistent with Merican and Rohaizat (2002) that private hospitals are available mostly in urban areas while the rural areas relied more on the limited public clinics and hospital facilities. The other option available such as nursing homes, day care centres, therapy and rehabilitation centres, and dialysis centres are rarely available in the neighborhoods. This warrants further investigation.

\section{Conclusion}

This study compares two types of caregiving for the elderly: formal and informal which exist in the Malaysian society. The latter system follows the oriental tradition in which is mainly performed by daughters. This could be 
the main reason why elderly prefer informal caregiving but at the cost about USD $\$ 330$ per month. In comparison, formal caregiving can cost more than USD $\$ 330$ and vary widely depending on the range and quality of service.

The main source of financial support for elderly may come from employee provident fund, pension fund and own savings. Therefore, it is imperative that government needs to review the employee provident fund, pension and mutual fund scheme in order to support those elderly who will require formal caregiving as society becomes more competitive for their children to provide informal caregiving. In conclusion, Malaysians government must realise that ageing should no longer be taken as a "welfare" issues but rather a collective social transformation trend that requires the collaboration of all fields ranging from healthcare, welfare, and the community.

\section{Acknowledgements}

The authors are grateful for the financial support received from Multimedia University. We thank Prof. Dr. Tou Teck Yong for valuable comments and suggestions.

\section{References}

Beard, J. (2010). A global perspective on population ageing. European Geriatric Medicine, 1(4), 205-206. http://dx.doi.org/10.1016/j.eurger.2010.07.003

Bernama. (2011, August 25). Malaysia prepare for ageing nation as world population reaches seven billion. Malaysia Today. Retrieved from http://www.malaysia-today.net/mtcolumns/newscommentaries/43055-malaysia-prepares-for-ageing-nationas-world-population-reaches-seven-billion

Boissy, P., Corriveau, H., Michaud, F., Labonté, D., \& Royer, M. P. (2007). A qualitative study of in-home robotic telepresence for home care of community-living elderly subjects. Journal of Telemedicine and Telecare, 13(2), 79-84. http://dx.doi.org/10.1258/135763307780096195

Camarinha-Matos, L. M., \& Afsarmanesh, H. (2002). Design of a virtual community infrastructure for elderly care. Proceedings of PRO-VE 3rd IFIP working conference on infrastructures for virtual enterprises. Retrieved from http://dare.uva.nl/record/104071

Chee, H. L. (2008). Ownership, control, and contention: Challenges for the future of healthcare in Malaysia. Social Science \& Medicine, 66(10), 2145-2156. http://dx.doi.org/10.1016/j.socscimed.2008.01.036

Chong, D. (2011, June 18). Full welfare state will bankrupt Malaysia, says Dr M. The Malaysian Insider. Retrieved from http://www.themalaysianinsider.com/mobile/malaysia/article/dr-m-says-full-welfare-state-will-bankrupt-ma laysia/

Choo, W. Y., Low, W. Y., Karina, R., Poi, P. J., Ebenezer, E., \& Prince, M. J. (2003). Social support and burden among caregivers of patients with dementia in Malaysia. Asia Pacific Journal of Public Health, 15(1), 23-29. http://dx.doi.org/10.1177/101053950301500105

Chuang, K. Y., Wu, S. C., Dai, Y. T., \& Ma, A. H. (2007). Post-hospital care of stroke patients in Taipei: Use of services and policy implications. Health Policy, 82(1), 28-36. http://dx.doi.org/10.1016/j.healthpol.2006.07.008

Collet, J., de Vugt, M. E., Verhey, F. R. J., \& Schols, J. M. G. A. (2010). Efficacy of integrated interventions combining psychiatric care and nursing home care for nursing home residents: A review of the literature. International Journal Geriatric Psychiatry, 25(1), 3-13. http://dx.doi.org/10.1002/gps.2307

Department of Social Welfare. (2011). Senior citizen and family institution. Retrieved from $\mathrm{http} / / / \mathrm{www} . j \mathrm{~km} . \mathrm{gov} . \mathrm{my} / \mathrm{index}$. php?option=com_content\&view=category\&id=61\&Itemid=68\&lang=en

Department of Social Welfare. (2012). National policy for the elderly. Retrieved from http://www.jkm.gov.my/index.php?option=com_content\&view=article\&id=86\%3Adasar-warga-emas-nega ra\&catid $=35 \% 3$ Adasarpelan-tindakan\&Itemid $=\overline{1289}$ \&lang $=$ en.

Gustafsdottir, M. (2011). Beneficial care approaches in specialized daycare units for persons with dementia. American Journal of Alzheimer's Disease and Other Dementias, 26(3), 240-246. http://dx.doi.org/10.1177/1533317511402315

Hanaoka, C., \& Norton, E. C. (2008). Informal and formal care for elderly persons: How adult children's characteristics affect the use of formal care in Japan. Social Science \& Medicine, 67(6), 1002-1008. http://dx.doi.org/10.1016/j.socscimed.2008.05.006 
Kuzuya, M., Izawa, S., Enoki, H., \& Hasegawa, J. (2012). Day-care service use is a risk factor for long-term care placement in community-dwelling dependant elderly. Geriatrics \& Gerontology International, 12(2), 322-329. http://dx.doi.org/10.1111/j.1447-0594.2011.00766.x

Matsui, M. (2010). Effectiveness of end-of-life education among community-dwelling older adults. Nursing Ethics, 17(3), 363-372. http://dx.doi.org/10.1177/0969733009355372

Merican, I., \& Rohaizat, Y. (2002). Health care reform and changes: The Malaysian experience. Asia-Pacific Journal of Public Health, 14(1), 17-22. http://dx.doi.org/10.1177/101053950201400105

United Nations. (2008). Population division of the department of economics and social affairs of the United Nations Secretariat, World Population Prospects: The 2008 Revision. Retrieved from http://esa.un.org/unpp/p2k0data.asp

Yip, C. (2012, April 28). Private pension funds for the financial future of senior citizens. The Star. Retrieved from http://biz.thestar.com.my/news/story.asp?file=/2012/4/28/business/11177415\&sec=business

Zaimi, A. R. (2007, August). Social welfare policies and services for the elderly: A country report (Malaysia). The 5th ASEAN \& Japan high level officials meeting on caring societies: collaboration of social welfare and health services, and development of human resources and community services for the elderly, 27-30 August 2007, Tokyo Japan. 